Conference Proceedings of the Society for Experimental Mechanics Series

Series Editor

Tom Proulx

Society for Experimental Mechanics, Inc.,

Bethel, CT, USA 

H. Sezer Atamturktur - Babak Moaveni - Costas Papadimitriou Tyler Schoenherr

Editors

\section{Model Validation and Uncertainty Quantification, Volume 3}

Proceedings of the 32nd IMAC, A Conference and Exposition on Structural Dynamics, 2014

包 Springer 


\section{Editors}

H. Sezer Atamturktur

Civil Engineering Department

Clemson University

Clemson, SC, USA

\section{Costas Papadimitriou}

Department of Mechanical and Industrial Engineering

University of Thessaly

Volos, Greece
Babak Moaveni

Department of Civil and Environmental

Engineering

Tufts University

Medford, MA, USA

Tyler Schoenherr

Sandia National Laboratories

Albuquerque, NM, USA
ISSN 2191-5644

ISBN 978-3-319-04551-1

DOI 10.1007/978-3-319-04552-8

Springer Cham Heidelberg New York Dordrecht London
ISSN 2191-5652 (electronic)

ISBN 978-3-319-04552-8 (eBook)

Library of Congress Control Number: 2014931235

(C) The Society for Experimental Mechanics, Inc. 2014

This work is subject to copyright. All rights are reserved by the Publisher, whether the whole or part of the material is concerned, specifically the rights of translation, reprinting, reuse of illustrations, recitation, broadcasting, reproduction on microfilms or in any other physical way, and transmission or information storage and retrieval, electronic adaptation, computer software, or by similar or dissimilar methodology now known or hereafter developed. Exempted from this legal reservation are brief excerpts in connection with reviews or scholarly analysis or material supplied specifically for the purpose of being entered and executed on a computer system, for exclusive use by the purchaser of the work. Duplication of this publication or parts thereof is permitted only under the provisions of the Copyright Law of the Publisher's location, in its current version, and permission for use must always be obtained from Springer. Permissions for use may be obtained through RightsLink at the Copyright Clearance Center. Violations are liable to prosecution under the respective Copyright Law.

The use of general descriptive names, registered names, trademarks, service marks, etc. in this publication does not imply, even in the absence of a specific statement, that such names are exempt from the relevant protective laws and regulations and therefore free for general use.

While the advice and information in this book are believed to be true and accurate at the date of publication, neither the authors nor the editors nor the publisher can accept any legal responsibility for any errors or omissions that may be made. The publisher makes no warranty, express or implied, with respect to the material contained herein.

Printed on acid-free paper

Springer is part of Springer Science+Business Media (www.springer.com) 


\section{Preface}

Model Validation and Uncertainty Quantification, Volume 3 represents one of the eight volumes of technical papers presented at the 32nd IMAC, A Conference and Exposition on Structural Dynamics, 2014, organized by the Society for Experimental Mechanics, and held in Orlando, Florida, February 3-6, 2014. The full proceedings also include volumes on Dynamics of Coupled Structures; Nonlinear Dynamics; Dynamics of Civil Structures; Structural Health Monitoring; Special Topics in Structural Dynamics; Topics in Modal Analysis I; and Topics in Modal Analysis II.

Each collection presents early findings from experimental and computational investigations on an important area within structural dynamics. Model Validation and Uncertainty Quantification (MVUQ) is one of these areas.

Modeling and simulation are routinely implemented to predict the behavior of complex dynamical systems. These tools powerfully unite theoretical foundations, numerical models, and experimental data which include associated uncertainties and errors. The field of MVUQ research entails the development of methods, with associated metrics, for the rigorous test of model prediction accuracy and robustness considering all relevant sources of uncertainties and errors through systematic comparisons against experimental observations.

The organizers would like to thank the authors, presenters, session organizers, and session chairs for their participation in this track.

Clemson, SC, USA

Medford, MA, USA

Volos, Greece

Albuquerque, NM, USA
H. Sezer Atamturktur

Babak Moaveni

Costas Papadimitriou

Tyler Schoenherr 



\section{Contents}

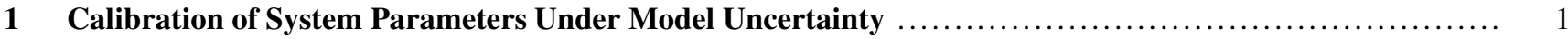

Ghina N. Absi and Sankaran Mahadevan

2 On the Aggregation and Extrapolation of Uncertainty from Component to System Level Models Angel Urbina, Richard G. Hills, and Adam C. Hetzler

3 Validation of Strongly Coupled Models: A Framework for Resource Allocation

S. Atamturktur and G. Stevens

4 Fatigue Monitoring in Metallic Structures using Vibration Measurements

D.C. Papadioti, D. Giagopoulos, and C. Papadimitriou

5 Uncertainty propagation in Experimental Modal Analysis

Bart Peeters, Mahmoud El-Kafafy, Patrick Guillaume, and Herman Van der Auweraer

6 Quantification of Prediction Bounds Caused by Model Form Uncertainty

Lindsey M. Gonzales, Thomas M. Hall, Kendra L. Van Buren, Steven R. Anton,

and François M. Hemez

7 Composite Fuselage Impact Testing and Simulation: A Model Calibration Exercise

Lucas G. Horta, Mercedes C. Reaves, Karen E. Jackson, Martin S. Annett, and Justin D. Littell

8 Noise Sensitivity Evaluation of Autoregressive Features Extracted from Structure Vibration

Ruigen Yao and Shamim N. Pakzad

9 Uncertainty Quantification and Integration in Multi-level Problems

Chenzhao Li and Sankaran Mahadevan

10 Reliability Quantification of High-Speed Naval Vessels Based on SHM Data Mohamed Soliman and Dan M. Frangopol

11 Structural Identification Using Response Measurements Under Base Excitation.... Suparno Mukhopadhyay, Raimondo Betti, and Hilmi Luş

12 Bayesian FE Model Updating in the Presence of Modeling Errors Iman Behmanesh and Babak Moaveni

13 Maintenance Planning Under Uncertainties Using a Continuous-State POMDP Framework Roland Schöbi and Eleni Chatzi

14 Achieving Robust Design through Statistical Effect Screening Kendra L. Van Buren and François M. Hemez

15 Automated Modal Parameter Extraction and Statistical Analysis of the New Carquinez Bridge Response to Ambient Excitations .

Yilan Zhang, Moritz Häckell, Jerome P. Lynch, and Raimund Rolfes 
16 Evaluation of a Time Reversal Method with Dynamic Time Warping Matching Function for Human Fall Detection Using Structural Vibrations

Ramin Madarshahian, Juan M. Caicedo, and Diego Arocha Zambrana

17 Uncertainty Quantification of Identified Modal Parameters Using the Fisher Information Criterion

Eric M. Hernandez and Néstor R. Polanco

18 Modal Parameter Uncertainty Quantification Using PCR Implementation with SMIT Minwoo Chang and Shamim N. Pakzad

19 Excitation Related Uncertainty in Ambient Vibration Testing of Bridges

Kirk A. Grimmelsman, James D. Lindsey, Ryan T. Dufour, and James T. Norris

20 Experiment-Based Validation and Uncertainty Quantification of Coupled Multi-Scale Plasticity Models ... 203 Garrison Stevens, Sez Atamturktur, Ricardo Lebensohn, and George Kaschner

21 Model Calibration and Uncertainty of A600 Wind Turbine Blades

Anders T. Johansson, Andreas Linderholt, and Thomas Abrahamsson

22 Validation Assessment for Joint Problem Using an Energy Dissipation Model Adam Hetzler, Angel Urbina, and Richard Hills

23 A Bayesian Damage Prognosis Approach Applied to Bearing Failure Zhu Mao and Michael Todd

24 Sensitivity Analysis of Beams Controlled by Shunted Piezoelectric Transducers

G. Matten, M. Collet, S. Cogan, and E. Sadoulet-Reboul

25 A Principal Component Analysis (PCA) Decomposition Based Validation Metric for Use with Full Field Measurement Situations

Randall Allemang, Michael Spottswood, and Thomas Eason

26 FEM Calibration with FRF Damping Equalization Thomas J.S. Abrahamsson and Daniel C. Kammer

27 Evaluating Initial Model for Dynamic Model Updating: Criteria and Application

Qingguo Fei and Dong Jiang

28 Evaluating Convergence of Reduced Order Models Using Nonlinear Normal Modes Robert J. Kuether, Matthew R. Brake, and Mathew S. Allen

29 Approximate Bayesian Computation for Finite Element Model Updating F.A. DiazDelaO, H.M. Gomes, and J.E. Mottershead

30 An Efficient Method for the Quantification of the Frequency Domain Statistical Properties of Short Response Time Series of Dynamic Systems M. Brehm and A. Deraemaeker

31 Quantifying Uncertainty in Modal Parameters Estimated Using Higher Order Time Domain Algorithms .. 317 S. Chauhan

32 Testing and Model Correlation of a Plexiplate with a Water Boundary Condition

C.D. Van Karsen, J.P. De Clerck, and S. Dhabe

33 Detection of Stress-Stiffening Effect on Automotive Components

Elvio Bonisoli, Gabriele Marcuccio, and Stefano Tornincasa

34 Approach to Evaluate Uncertainty in Passive and Active Vibration Reduction

Roland Platz, Serge Ondoua, Georg C. Enss, and Tobias Melz

35 Project-Oriented Validation on a Cantilever Beam Under Vibration Active Control 
36 Inferring Structural Variability Using Modal Analysis in a Bayesian Framework H.M. Gomes, F.A. DiazDelaO, and J.E. Mottershead

37 Including SN-Curve Uncertainty in Fatigue Reliability Analyses of Wind Turbines Jennifer M. Rinker and Henri P. Gavin

38 Robust Design of Notching Profiles Under Epistemic Model Uncertainties Fabien Maugan, Scott Cogan, Emmanuel Foltête, Fabrice Buffe, and Gaëtan Kerschen

39 Optimal Selection of Calibration and Validation Test Samples Under Uncertainty 391 Joshua Mullins, Chenzhao Li, Sankaran Mahadevan, and Angel Urbina

40 Uncertainty Quantification in Experimental Structural Dynamics Identification of Composite Material Structures Marcin Luczak, Bart Peeters, Maciej Kahsin, Simone Manzato, and Kim Branner

41 Analysis of Numerical Errors in Strongly Coupled Numerical Models 409 Ismail Farajpour and Sez Atamturktur

42 Robust Expansion of Experimental Mode Shapes Under Epistemic Uncertainties 419 A. Kuczkowiak, S. Cogan, M. Ouisse, E. Foltête, and M. Corus 